\title{
The Building Process: A New Direction In Architectural Education
}

\author{
HAJO NEIS \\ University of California, Berkeley \\ USA
}

\begin{abstract}
The Building Process was formally established as an Area of Emphasis by the Department of Architecture at Berkeley in 1988 with Christopher Alexander as the head. This step was taken in recognition of changing demands in architectural education and practice and the need to investigate design, planning and construction as one integrated process. Hajo Neis joined this new area in 1990 as a faculty, and describes the development, achievements and current state of this new direction in architectural education and its connection to architectural research and practice.
\end{abstract}

\section{INTRODUCTION}

The 'Building Process' arose as a new direction in architectural education, practice and research from a need to give new life and meaning to the profession and consequently to the teaching of architecture.' This new meaning has at its heart the investigation, development and implementation of processes of design and making which explicitly attempt to create a 'living' architecture in the structure of the environment, and which create for us and in us a 'sense of belonging.'

In the 'notes from the editor' of the first volume of the new informal Process Studies Journal, Alexander states:

We may describe the best situation in the environment, as one where we experience emotional possession of the world, or 'belonging.' It is a state in which the fine adaptation between people and their buildings and gardens and streets is so subtle, and goes so deeply to the core of human experience, that the people who live and work and play in that environment feel as if they belong there, as if it belongs to them, as if they are part of it, as if, like an old shoe, it is completely and utterly theirs. ${ }^{2}$

We have to recognize that this quality of sense of belonging came about, historically, as a result of a rather long process. It is essentially a process of place making, which was carried out gradually and in continuous adaptation by people and between people and their places. Such a process based on historical precedent is hardly available any more in our times. Time itself in the modern world has become much faster and process with it; society evolves faster, people move faster, and buildings and environments change faster.

Process in design and making in the twentieth century has become increasingly fractured, fragmented and specialized.
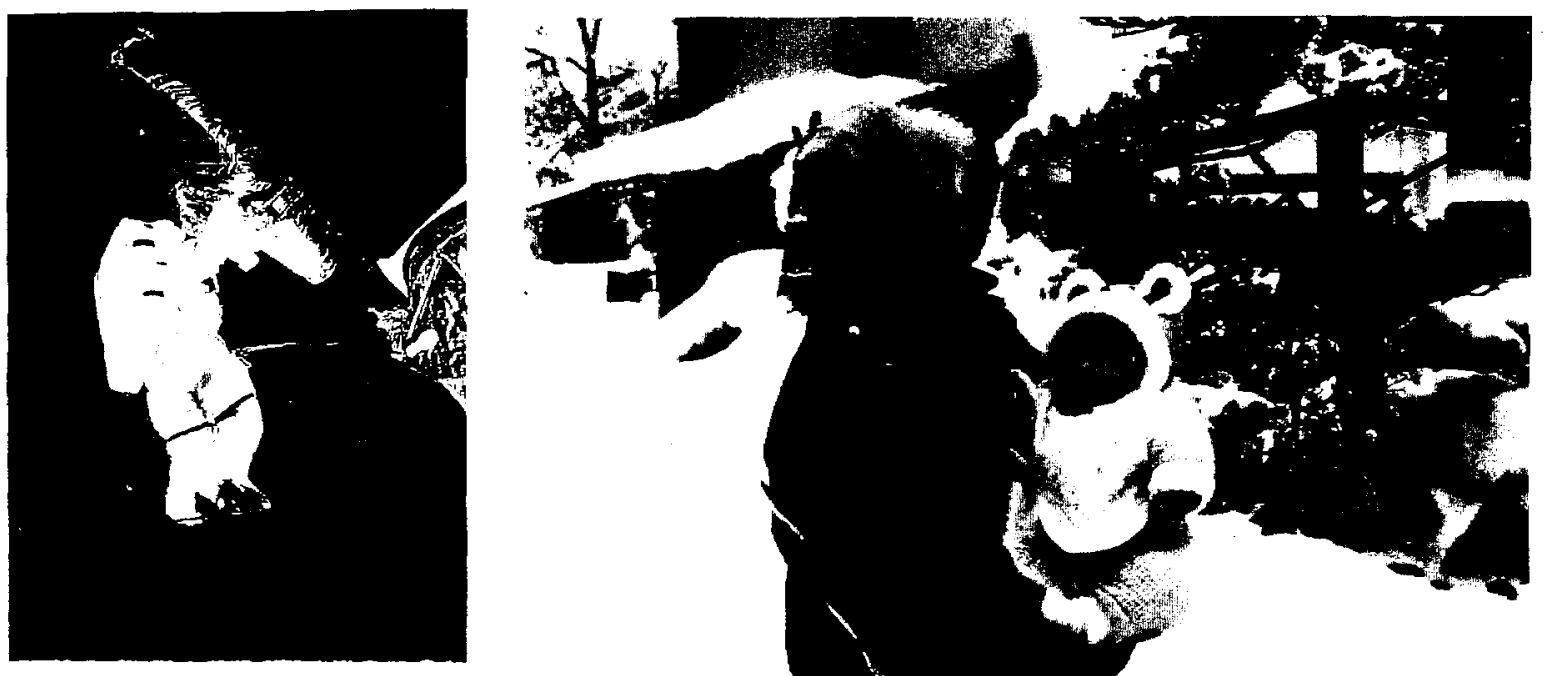

Fig. 1. Finding a 'sense of belonging' in the 21 st century and beyond. 
Small bits and unrelated parts have become the focus of attention rather than the whole and the whole begins to dissolve at all levels of scale. The result manifested in the built environment has been an increasing abstraction and separation of buildings from the environment. The result in the lives of people has been an increasing alienation from the environment and each other.

The old process which created a sense of belonging is probably outdated. If we want to create sense of belonging, today, it must be a new process. We have to investigate new kinds of processes, which may create the connection to place and the earth again in some form. And, we need to investigate the modern means which are capable of establishing such processes.

The fundamental basis of the Building Process is that it is possible to give a coherent answers to the essential questions: What kind of structure must the environment have to support life? and, What kind of process(es) create life in the structure of the environment? Everything in the program follows from the answers to these questions.

Quality in architecture and the built environment is dependent on the process which generates it. The fundamental characteristic of this process is that design, construction and planning are carried out as one unified act of building and making. Consequently, this process may be defined as an integrated process of design and construction, and also theory and planning, for the formation of quality in buildings and the built environment. Hence, we call this approach the Building Process.

\section{FOUNDATIONS OF THE "BUILDING PROCESS"}

The Building Process approach in architecture, and hence the approach in architectural education, in its current form, has coalesced from the results of nearly three decades of ongoing research and implementation, all of which is based on determining answers to the questions: What is a good structure? What process creates good structure? and, What process is needed to apply it? The results, as well as the open questions, form the foundation of the Building Process.

\section{Search for Quality: What Is a Good Stucture?}

The first question -- What kind of structure must the environment have to support life? -- is the starting point of our work. What are the structural properties of form and space that create good environmental structures at every level of scale? What is a good structure or what constitutes a good building? Where does quality, profound quality, a deep feeling in a town, a building, or a window seat come from? Why does one kind of building make us more at peace with ourselves than another one, and why is one building considered a better mirror of one's inner-self than another? Research on these questions has been done along two lines of investigation.

The first line of investigation was done with regard to space, geometry, color, and the nature of matter. Here the questions were: What kind of geometrical and spatial properties can be found in so called beautiful buildings, and good environments? And, what are the fundamental and shared characteristics of good artifacts, elements in nature,

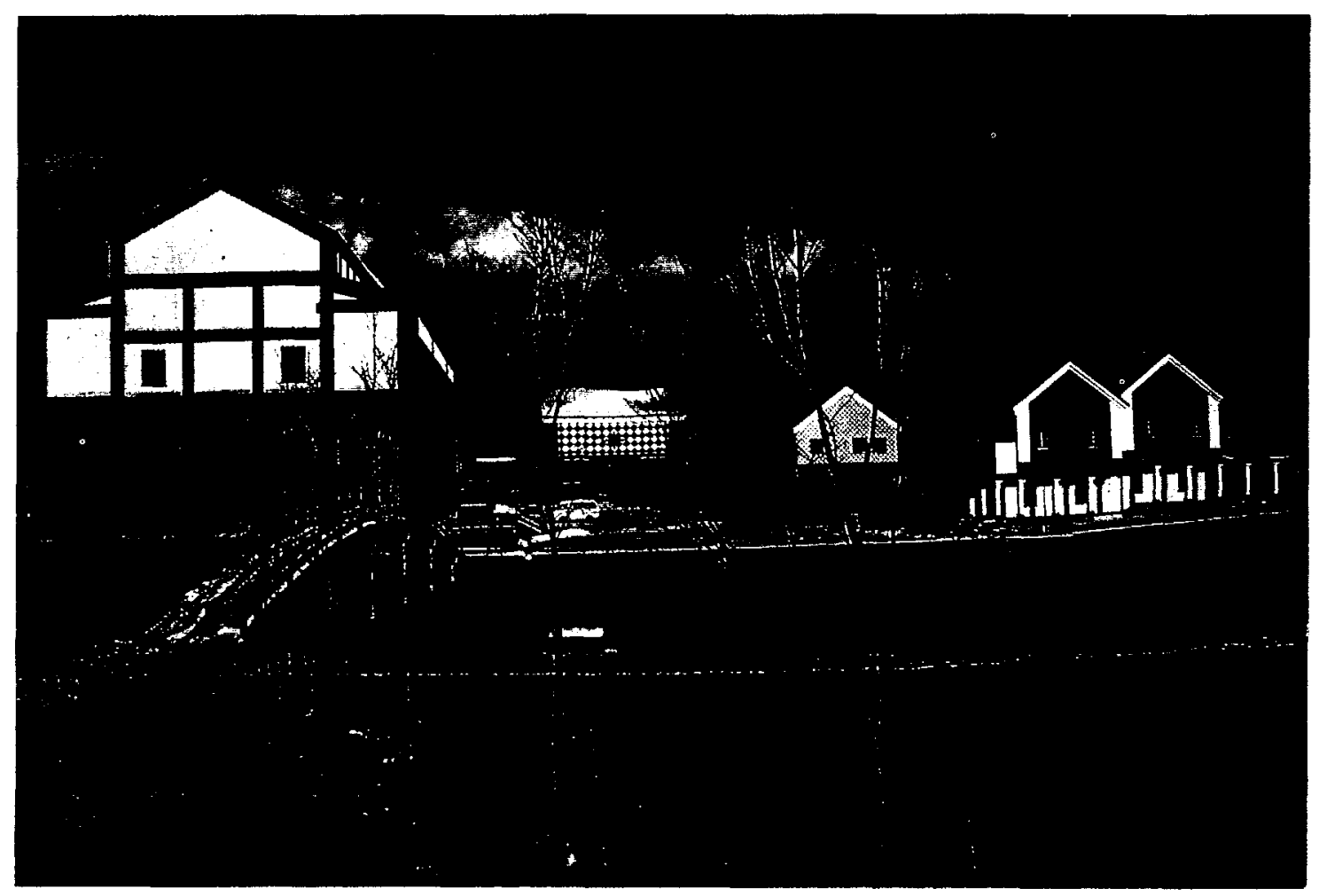

Fig. 2. The Eishin School campus in Tokyo. CES. 
and buildings that provide more centeredness and wholeness than others? As one answer to this question, the research of Christopher Alexander shows that it is particular structural geometrical features which appear to be responsible for profound quality in built environments, nature, buildings, interior rooms and artifacts. Based on earlier research of the 'gestalt psychologists' ${ }^{3}$ who investigated characteristics of laws of perception (like wholeness, praegnance, good gestalt, etc.), Alexander provides us with fifteen geometrical properties of space and form (such as, boundaries, centers and subsymmetries), which are present in configurations of buildings and environments with profound quality. The nature and characteristics of this geometrical structure are reported in depth in BOOK 1 of The Nature of Order, ${ }^{4}$ color properties are also further presented in $A$ Foreshadowing of 21 st Century Art. ${ }^{5}$

The notion of wholeness or profound quality is central to the understanding of good environments, beautiful buildings and artifacts. Wholeness or organic order is of course a very old notion described and defined in various versions by Aristotle, Augustinus, Alberti and others, and also by Frank Lloyd Wright in this century. ${ }^{6}$ In its most recent form, wholeness has been defined by Alexander as the main characteristic of a 'field of centers.' The more precise and substantive notion of centers and fields of centers can then be defined as the geometrical or structural expression of wholeness or profound quality in the environmental structure.

The second line of investigation had begun earlier - in the nineteen sixties - according to a functional approach. The questions in this case were: What kind of environments are comfortable, work well and therefore have a deep connection to human feeling? And, which of these environments can be observed repeatedly as archetypal solutions to building problems. What are the functional characteristics of such environments? The results of this investigation were reported in A Pattern Language in which about 250 of these environments were compiled and interrelated?

Patterns may be described as functional solutions to environmental context problems, in earlier versions these patterns were also called 'atoms of the environment'. The relationship between 'pattern' and 'type' is described by Habraken:

Where a type comprises a number of similar elements combined into an organic whole, patterns are deployments of specific elements in the same relation across the field. Usually the elements forming patterns are either larger than the house, such as streets and squares, or smaller than the house, such as rooms and atria. ${ }^{8}$

These archetypal patterns cover four areas of the built environments: Regions and cities, urban areas and neighborhoods, buildings and spaces, construction, engineering and materials. For example, pattern number 1 -- "Independent Regions" -- describes a solution for the need of independent cultural and administrative regions in the world. Pattern number 106 -- "Positive Space" -- describes the crucial relationship of buildings and the urban spaces they shape and create. Pattern number 112 -- "Entrance Transition" -describes a solution for the need of balance between private and public; and, pattern number 235 -- "Soft Inside Walls" - describes the relationship of human comfort and soft materials. Patterns can be used in various combinations almost language-like - by architects, users, and clients for creating their own particular environments. Also, several design guideline books have tried to work with this structure of observation. ${ }^{9}$

While patterns are first of all derived from functional arguments, they also can be understood geometrically and spatially -- as fields of centers. Function and geometry combined is then understood under one category. With this deeper understanding the key answer to the question of what is a good structure is given by the notion of a center or a field of centers. A good structure, a structure which is capable of supporting life is defined as a field of centers.

\section{Search for Process: Processes which Create Good Structures}

The second question -- What kind of process(es) creates life in the structure of the environment? -- follows from the first. What processes of growth and transformation yield the profound quality found in nature, buildings, artifacts, the environment, and also drawings and design? Which processes are capable of generating good environmental structures and buildings? And what are the characteristics of good processes? What are the design and building processes which are capable of generating good environments?

Process in twentieth century thought has become prominent with the writing of Whitehead in Process and Reality, ${ }^{10}$ which is his cosmology and considers everything in terms of process; and - more than 2000 years ago - it was Heraklith who made the intriguing observation that one never can step into the same river twice. The gestalt psychologist Wertheimer observed that 'a melody is a whole, that is more than the sum of its parts.' D'Arcy Thompson, in his seminal work On Growth and Form ${ }_{2}$ in which he formulated essential characteristics of growth in nature and biology, emphasizes that every form at every stage is essentially the outcome of a growth process."

A Growing Whole. The idea of 'a growing whole' was formulated on a basic level, giving structure to the general process of growth in design, planning and construction. At the heart of the search for process is the idea of a generative process, that is a process which has a few basic components or information, as in DNA, which is capable of generating an unlimited variety of life, form and process. A Pattern Language was conceived as such a generative 'language' in the functional area of design, which can generate a complex built environment from a limited number of patterns.

Creating Wholes. On the level of pure geometrical growth and design processes (including the employment of 
the fifteen properties), the principles of 'formation of centers, ' and 'fields of centers' or 'the formation of wholes' were tested first. The process must keep the formation of the whole, its geometrical and emotional value structure, always foremost. The process of the formation of centers and fields of centers helps to create spatial and geometrical structures with profound quality. Profound quality in the geometrical structure of form and space arises from the formation of closely interrelated centers or wholes at every level of scale

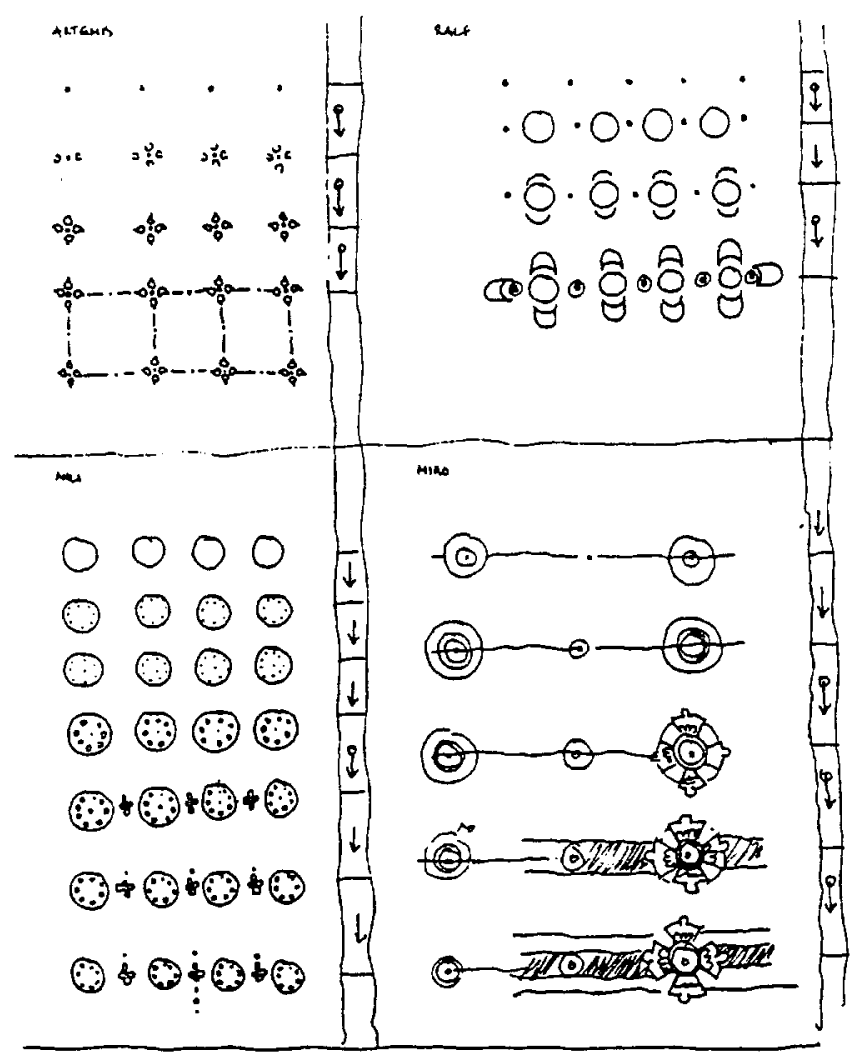

EXFERIMENT

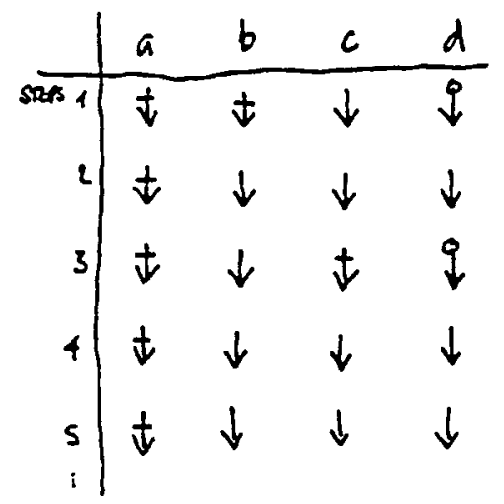

I stucosere curturcions $\downarrow$ Thansforniand $\downarrow$ grencinat ratseaving

Fig. 3. Experiment and analysis by four participants in making a series of structure preserving transformations starting from a set of points. from the small to the great. With each act of design or construction of an emerging center one should also help to create three other centers at different scales, one at a larger scale, others at the same scale, and still others at a smaller scale.

Continuous Growth and Adaptation. Continuous feedback and change to fit local circumstances is an essential feature of processes which create wholes. A process of continuous growth and adaptation sequential, each step responding to and building on the reality created in the preceding step. At the fine level of structure, the ultimate form is unpredictable as adaptation to local conditions occurs throughout the process of growth. A structure that does not evolve in a process of continuos feedback and exchange becomes arbitrary, lacks life and is separate from both the local and the larger environment.

Essential to the understanding of processes and good processes is this notion of transformation. Designing and building is essentially a continuous series of transformations. The principle of 'Structure Preserving Transformations' is one of several tools which help guide this process of transformation toward the creation of centers. The principle is made concrete in three rules which one carefully applies over and over again:

1. The first rule says, that with each act of placing an increment of design or construction, we have to understand and respect the existing structure of what is there so far.

2. The second rule says, that with each act of placing an increment of design or construction, we also have to preserve the existing structure.

3. The third rule says that we not only have to preserve the existing structure, but we also have to enhance the existing structure of what is there so far.

A very basic example illustrates this principle starting from a set of points (Fig. 3). Each step can be checked with regard to the criteria of preserving or not preserving, preserving and not enhancing, or preserving and enhancing such that a greater and denser field of centers is created in the emerging whole.

From the basic research in structure and process, major principles, or more simply, variables, were formulated for application. These include the principles of organic order, piecemeal growth, step-by-step formation, formation of centers and fields of centers, structure preserving transformations, pattern language/project language and participation.

Participation of users and clients is an essential component to integrate the value structure of participants into a project. The principle of participation, for example, is essential in the formation of a Pattern Language or a Project Language for a given project. Creating a Project Language expands on the idea of a pattern language in that it distills and describes from user comments and the existing environmental structure the essence and spatial character for a specific building project and defines its connection to its participants and the environment as a whole. 
Questions of planning and zoning were researched, the social and political decision making process was investigated, and the construction process itself was researched in its potential to form larger wholes. Early projects in which various sets of these principles were applied in professional projects, include the long range plan for the development of the University of Oregon, involving users and patterns, which was reported in The Oregon Experiment ${ }^{12}$ the Peru Housing project for the United Nations Habitat Program and the innovative People Rebuilding Berkeley Project in which the flow of money was critically investigated and, consequently, the decision making process of money distribution was shifted from the public works departments to the neighborhoods and citizen groups in Berkeley. In another innovative project, the process of organic growth or piecemeal development of part of a city is documented in $\mathrm{A} \mathrm{New}$ Theory of Urban Design. ${ }^{13}$

\section{The Building Process: Applied Architectural Processes which Create Good Rooms, Buildings, Streets, and Towns}

The third question -- What kind of applied process(es) can create life in the structure of the environment? -- is the question of building and implementation. What kind of design, building and construction processes are capable of helping to create profound human quality in a building, a gate, a garden house? How do we actually apply structure and process so that we finally achieve good built structures, good buildings? How do we go about creating good buildings, good rooms, windows and entrance doors with value and solidity? What kind of design and construction process together as one process is capable of achieving this quality?

Continuous Design and Construction. It is actually this third question which has lead to the definition of the building process as one integrated process of design and construction, theory and planning. Here, research has shown that it is actually the building process (the process of design and construction together) which is largely responsible for the creation of wholeness or profound quality in buildings. ${ }^{14}$ It is a process in which design and construction are thoroughly intertwined and in which the design encourages the construction and the construction encourages the design. It is a building process in which fine adaptation occurs all the time, not only in the design process but particularly so in the construction process according to the need of the emerging quality or the emerging whole. ${ }^{15}$

New Process. Any new kind of architectural process needs to investigate the intricate relationship between design and construction and the construction process itself with all its critical components. The main focus of such a process is orchestrating the complete development of an emerging whole. To do so one must manipulate critical elements of process, such as the construction method, construction systems, construction techniques and procedures, engineering, design and construction contracts, cost estimates and cost control, and new forms of construction management.

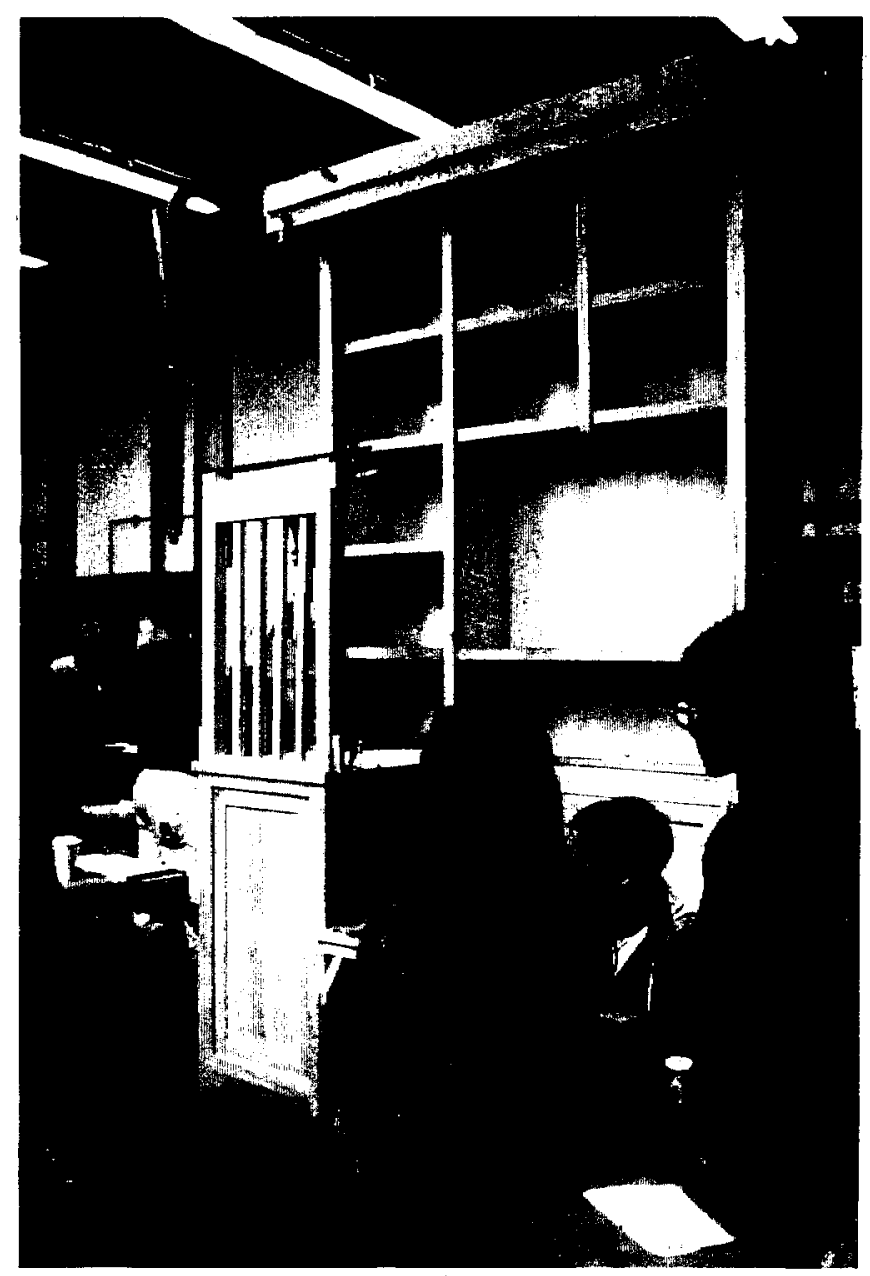

Fig. 4. Continuous design and construction of a stepped library furniture piece. Hajo Neis with students.

It is the dynamic quality of the design and construction process, and the role of the design and construction components within this process, which is the essence of new process. Construction methods, that is the legal and contractual relationships under which a project is constructed, such as the GC (general contractor) method need to be investigated further with regard to their potential of achieving quality. New methods for the formation of good quality buildings, such as the ACM (architect construction manager) Method, which permits the architect to also manage the construction, have been implemented and need to be established.

Standard construction systems and techniques, such as concrete, steel or wooden systems need to be investigated with regard to their potential for creating quality, and new construction systems, such as mixed concrete/wood or concrete/steel systems need to be explored. Detailed engineering with new kinds of computer programs, such as finite element analysis have been used with success and need to be explored for further potential. ${ }^{16}$

New methods of dynamic cost estimates and dynamic cost control have lead to new and innovative solutions of managing a project budget to achieve the greatest quality and 
essence of the whole, such as the method of the 'uneven distribution of money' in which some elements with a major impact on the belonging quality of the emerging whole could be rather costly, while others with minor impact may be very cheap and unfinished.

New process needs to investigate the potential of new technologies, new materials and machinery to speed up the process of design and construction without loosing the essence of process qualities - the direct experience, which creates quality. The role and the use of mock-ups (full scale mock-ups to test and develop form, detail, and structure) needs to be defined for critical parts of the process to ensure the quality of the growing whole.

New process also needs to investigate new roles for architects and builders, such as the architect as a builder, and the role of the architect as a design and construction manager, who understands the needs and dynamics of the emerging quality of a building or a larger project. Such an investigation may also lead to the formulation of new kind of construction contracts, and new kinds of construction management with emphasis on the integration of design and construction at the appropriate level.

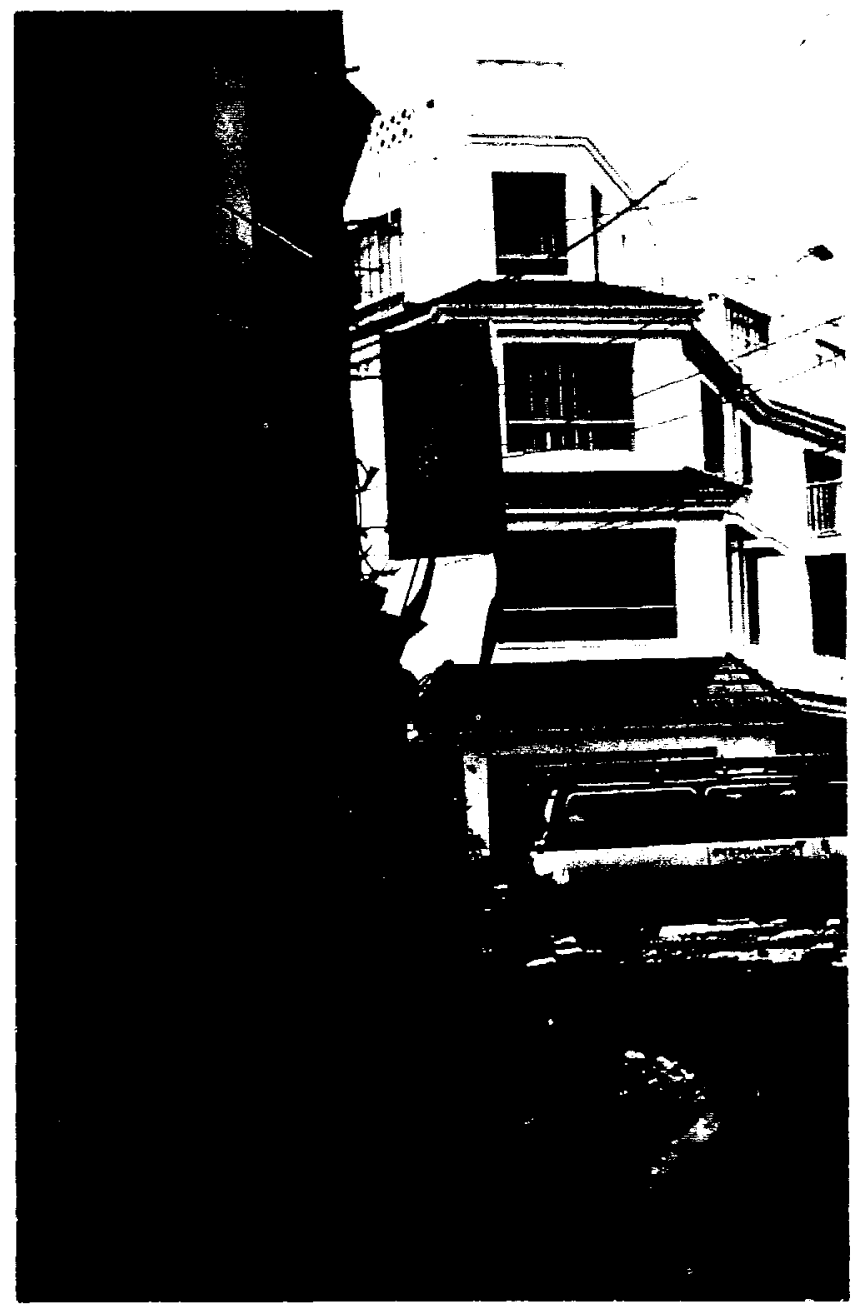

Fig. 5. The Emoto apartment building in Tokyo, shaping living urban space. CES Japan and Hajo Neis.
Projects. At an early stage, a low-cost housing project was carried out in Mexicali, Mexico in which many of these new variables were applied. ${ }^{17}$ For the first time a project showed real potential for profound quality in buildings through the detailed integration of design and construction. Key to the success of this project was that the architect/ contractor had control over the following elements: control over planning, control over zoning, control over lot subdivision, control over design, control over structural engineering, control over materials testing and development, control over manufacturing, control over building permits, control over construction, control over accounting and some parts of loan approval. Having control over these elements was instrumental in creating a larger whole.

Additional projects of this kind have been accomplished in the US and other countries, in particular the Martinez field station buildings, the Albany house, the Poppy Lane House in Berkeley by Christopher Alexander and CES, the Sakura Tsutsumi Building in Tokyo by Hajo Neis, and the Cultural Park Project in Cairo by Halim. In larger projects, this integrated approach was successfully applied in the Eishin College Campus in Japan, ${ }^{18}$ the Emoto Apartment building in Tokyo, and the Shelter for the homeless in San Jose. In large planning projects, many of these variables were applied in the Guasare new Town project in Venezuela, the Moshav Morashim in Israel, the Amazon Student Village in Eugene Oregon, and in the Wertheimer Tor Project in Germany.

\section{CURRICULUM AND TEACHING IN THE BUILDING PROCESS}

Major Characteristics of the Building Process Approach in Architecture and Architectural Education

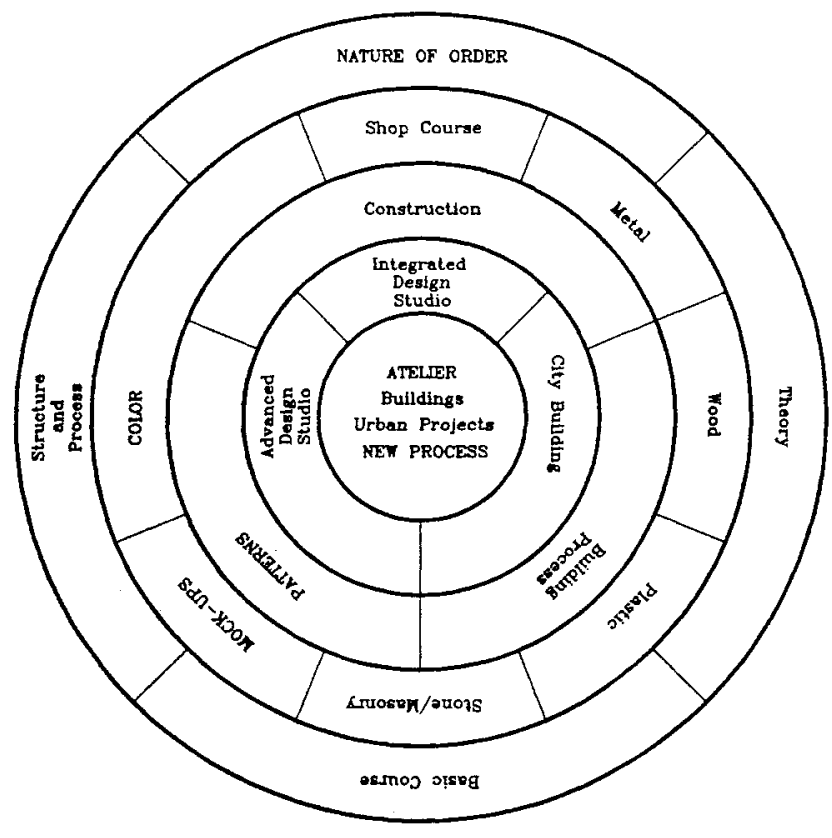

Fig. 6. Concentric diagram illustrating the curriculum in the Building Process with several progressive layers of learning. 
From the three major areas, which form the foundation of the Building Process: structure, process and implementation, we can identify major characteristics for architectural education:

Architecture is approached from the understanding of the qualities of wholeness in the environmental structure. Wholeness can be understood through the innate structure of space, geometrical properties and color. The process of design, building and making is the process of creating wholes in the environment.

Architecture is defined as the process of the formation of fields of centers at all levels of scale which create larger wholes. The principle of Structure Preserving Transformations is applied as one guide to the process of the formation of wholes as fields of centers at all levels of scale, from a small artifact to an urban structure. Unpredictability of form and variation is given through the step by step process of continuous growth and adaptation.

Architecture is functionally derived from a Pattern Language, and Project Language, including Type and Typology. Design is based on analysis of the specific structure in the environment and its relationship to human experience as the foundation for creating quality in any project. Participation of users is essential.

Architecture is a process of continuous and integrated design and construction, and architecture as in large scale projects and urban projects is defined as a process of integrated planning, design and construction. Variety and unity of form arises out of the unified process of planning, design and construction.

Architecture is developed as the art of making. Teaching architecture as the art of making directly engages the human experience of the architect, client, and society, creating buildings liked by people. Design is developed directly from work with the media of the art of architecture. Design is developed to a large degree in full-scale mock-ups directly on site and in scale working models to create buildings and space as a three-dimensional reality.

Architecture requires creating innovative construction systems and details of construction to create wholes in the local and global environment. Connected to the study of structures, computer based finite element analysis can be used as a tool for creating a deep integration of space and structure.

Architecture is a process of innovative construction management. A process of dynamic cost control, such as "the uneven distribution of money," is necessary to create wholes within a given budget. Standard contractual relationships are redefined to achieve the integration of design and construction as a continuous process.

Architecture is felt and understood as something which can really improve the world around us in the very small and the very large. A sense of belonging and connection to the world is achieved through the Building Process for the clients, users, architects, builders, passers by and future generations.

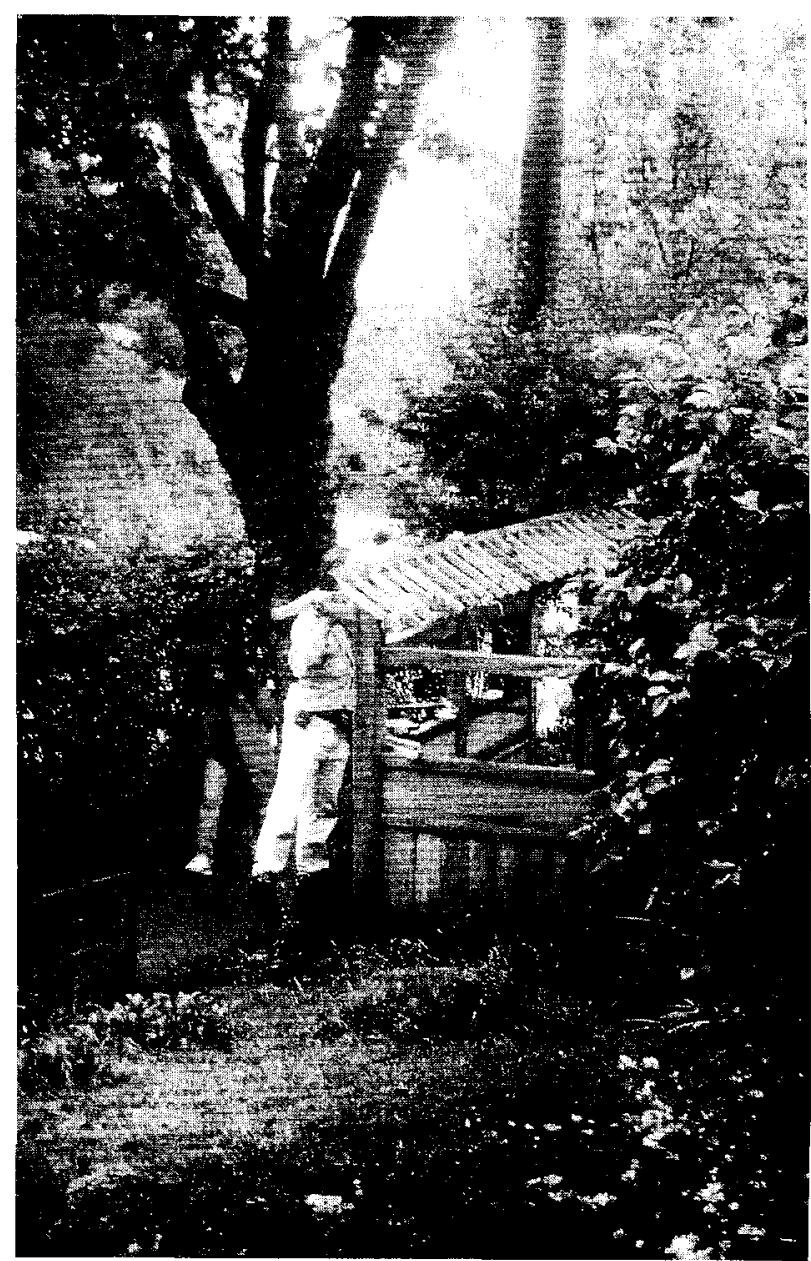

Fig. 7. Students designing and building a garden wall and entrance gate.

\section{Courses in the Building Process}

The curriculum of the Building Process can be illustrated in a concentric diagram with several layers of progressive learning. This diagram is formally similar to the diagram developed by the Bauhaus in the nineteen twenties but differs with regard to the contents and the emphasis on process and new process. ${ }^{19}$ The outer core or entry is formed by a lecture series on the Nature of Order in which students learn the theory of profound quality, theory on processes which generate quality, and theory of building implementation. At the inner core of this diagram is the Atelier and New Process, in which students learn to apply structure and process in real world projects and explore new processes necessary for the success of the project.

\section{CONCLUDING REMARKS}

The aim of the Building Process area of emphasis is to provide an architectural education which is based on the integration of design, construction, planning and theory for the formation of quality in buildings and the environment. Emphasis is on the understanding of architecture as process, including the exploration of new process. The question is 


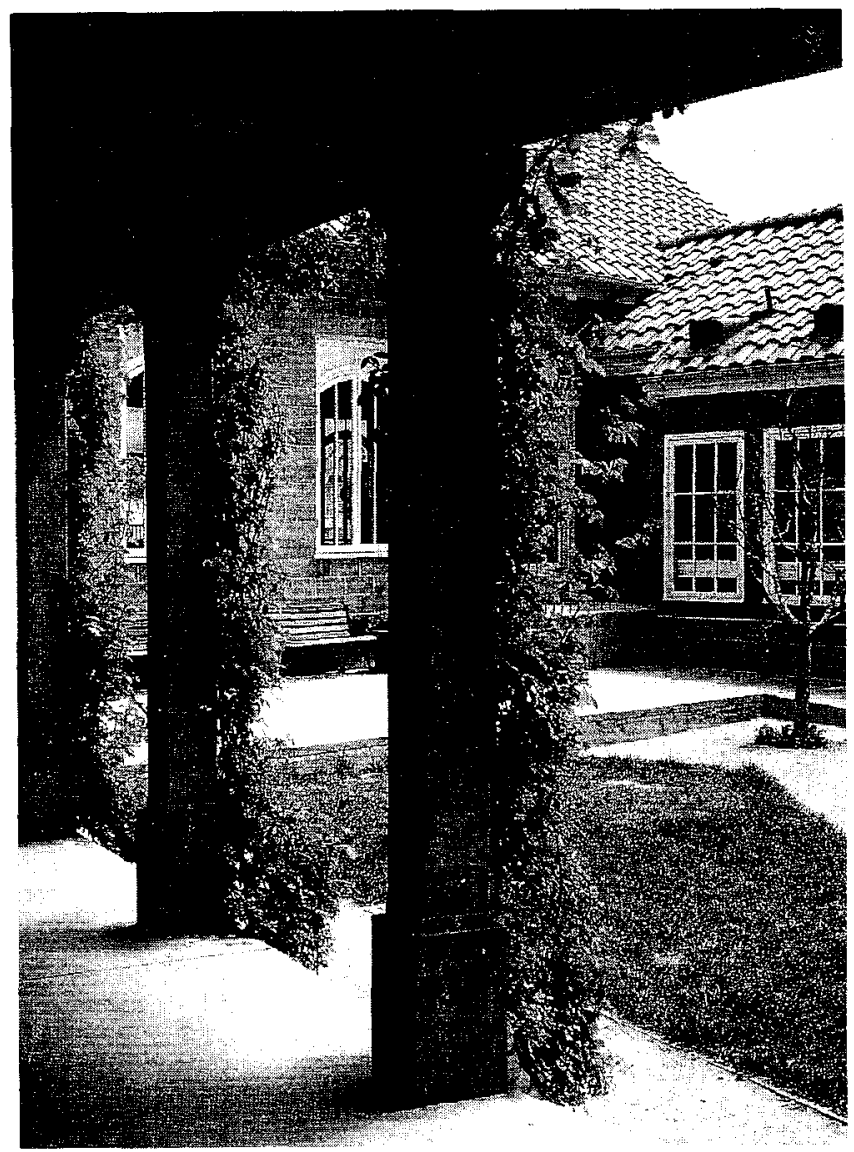

Fig. 8. Interior courtyard of the Julian Street Inn, shelter for the homeless. CES.

what are we getting here in terms of architectural education, what kind of architects come out of this program, and most important of all, what kind of architecture are we getting from the Building Process approach?

Some architects accept the acceleration of process and the fragmentation of our environment as the signs of the times, and see it, if not as a positive development, then at least as the real development which we should use for new opportunities in design and architecture, specifically, for the exploration of new forms. ${ }^{20}$ While the exploration of new forms for the purpose of creating new form is one thing, the exploration of new process for the purpose of creating a living architecture is another. The former does not exclude new process, the latter does not exclude new form. It is the purpose which is different.
This paper was made possible with an COR Grant from UCBerkeley and with the assistance of Christopher Gutsche and Susan Ingham from my office.

\section{NOTES}

I Paulhans Peters, "Patterns and Postmodern - on Christopher Alexander's attempt to give new content to the profession of architecture," Baumeister. (Munich, 1988), pp. 6-8.

${ }^{2}$ Christopher Alexander, "Notes From the Editor," Process Studies - A Journal of Architectural Process. Vol. 1 (University of California, Berkeley: Fall, 1994).

${ }^{3}$ See for example: Koffka, Principles of Gestalt Psychology (New York: Harcourt, Brace \& World, 1963).

${ }^{4}$ Alexander, The Nature of Order (Unpublished manuscripts at UC-Berkeley, 1992).

5 Alexander, A Foreshadowing of 21st Century Art (New York: Oxford University Press, 1993).

" Frank Lloyd Wright, "Organic Architecture and the Orient," selected by Edgar Kaufman and Ben Raeburn, Frank Lloyd Wright: Writings and Buildings (New York: Mendian Books, 1960), p. 298.

${ }^{7}$ Alexander, Ishikawa, Silverstein, et. al., A Pattern Language (New York: Oxford Univerśity Press, 1977).

${ }^{8}$ John Habraken, "Cultivating the Field: About an Attitude When Making Architecture," Places. Vol. 9, No. 1 (Winter, 1994), p. 10.

${ }^{9}$ Cooper Marcus, Sarkisan, Housing As If People Mattered (Berkeley: University of California Press, 1986).

10 Alfred Whitehead, Process and Reality (New York: The Macmillan Co., 1957).

$"$ D' Arcy Thompson, On Growth and Form (Cambridge: Cambridge University Press, 1942).

12 Alexander, Ishikawa, et. al., The Oregon Experiment (New York: Oxford University Press, 1975).

13 Alexander, Neis, et. al., A New Theory of Urban Design (New York: Oxford University Press, 1987).

14 For a detailed discussion see: Artemis Anninou, "The Unified Building Process," (Ph.D. Diss., UC-Berkeley, 1986).

${ }^{15}$ Hajo Neis, "City Building: Models for the Formation of Larger Urban Wholes," (Ph.D. Diss., UC-Berkeley, 1986).

${ }^{16}$ Gary Black, Stephen Duff, "A Model for Teaching Structures: Finite Element Analysis in Architectural Education," Journal of Architectural Education. (Sept., 1994), pp. 38-55.

17 Alexander, et. al., The Production of Houses (New York: Oxford University Press, 1985).

${ }^{18}$ Alexander, Neis, et. al., Battle: A Crucial Clash Between World System $A$ and World System B (Book ms, Berkeley, 1994).

19 Hans M. Wingler, The Bauhaus (Cambridge: MIT Press, 1986), p. 52.

2n See for example: Rem Koolhaas, Whatever Happened to Urbanism? (forthcoming from Monacelli Press). 